\title{
Nickel-catalysed reactions with trialkylboranes and silacyclobutanes
}

\section{AUTHOR(S):}

Hirano, Koji; Yorimitsu, Hideki; Oshima, Koichiro

\section{CITATION:}

Hirano, Koji ...[et al]. Nickel-catalysed reactions with trialkylboranes and silacyclobutanes. Chemical Communications 2008, 2008(28): 3234-3241

\section{ISSUE DATE:}

2008-07

URL:

http://hdl.handle.net/2433/88966

\section{RIGHT:}

Copyright (C) 2008 Royal Society of Chemistry. Koji Hirano, Hideki Yorimitsu and Koichiro Oshima, Chemical

Communications, 2008(28), 2008, 3234-3241. http://dx.doi.org/10.1039/b803172j - Reproduced by permission of The

Royal Society of Chemistry; This is not the published version. Please cite only the published version.; この論文は出版社 版でありません。引用の際には出版社版をご確認ご利用ください。 


\title{
Nickel-Catalysed Reactions with Trialkylboranes and Silacyclobutanes
}

\author{
Koji Hirano, Hideki Yorimitsu,* and Koichiro Oshima* \\ Received (in XXX, XXX) 1st January 2008, Accepted 1st January 2008 \\ First published on the web 1st January 2007 \\ ${ }_{5}$ DOI: 10.1039/b000000x
}

Nickel catalysis enables us to develop new reactions with trialkylboranes and silacyclobutanes of modest reactivity. A combination of $\mathrm{Ni}(\operatorname{cod})_{2}$ and tri-t-butylphosphine catalyses alkylation reactions of aldehydes and $\alpha, \beta$-unsaturated esters with various trialkylboranes of modest reactivity, suppressing conceivable $\beta$-hydride elimination from alkylnickel intermediates. A nickel catalyst is 10 also useful for 1,4-addition of bis(pinacolato)diboron to $\alpha, \beta$-unsaturated esters and amides.

Nickel-catalysed reaction of silacyclobutanes with aldehydes results in ring opening to afford the corresponding alkoxyallylsilanes. In contrast, the ring expansion reaction of benzosilacyclobutene with aldehydes yields benzoxasilacyclohexenes. A nickel catalyst prepared from $\mathrm{Ni}(\mathrm{cod})_{2}$ and tricyclohexylphosphine realises direct silylation of terminal alkene with silacyclobutane furnishing 15 vinylsilanes.

\section{General introduction}

Taking advantage of their excellent and/or unique reactivity, molecular nickel catalysts have been attracting increasing attention in organic synthesis. ${ }^{1}$ Among nickel-catalysed 20 reactions, cross-coupling and carbometalation reactions, in a broad sense, with organometallic reagents provide powerful and reliable tools for carbon-carbon bond formation. A variety of organometallic reagents such as organomagnesium, -zinc, -aluminum, -silicon, and -boron reagents are now 25 available for use under nickel catalysis. However, to expand scope, and to establish universal organic synthesis, further studies on nickel-catalysed reactions are essential. In light of the importance of moderately reactive organoboron and silicon reagents, we have focused on nickel-catalysed 30 reactions with these reagents. This account consists of two sections. The former section deals with nickel-catalysed alkylation reactions of carbonyl compounds with trialkylborane. The latter describes nickel-catalysed reactions of unsaturated compounds with silacyclobutanes.

\section{${ }_{35}$ 2. Nickel-catalysed alkylation reactions with trialkylboranes}

\subsection{Overview of organoborons under nickel catalysis}

Compared to palladium ${ }^{2}$ and rhodium, ${ }^{3}$ nickel catalysts were far less frequently used for reactions with organoborons: 40 cross-coupling reactions of aryl tosylates and mesylates ${ }^{4}$ and alkyl halides, ${ }^{5}$ allylic arylation, ${ }^{6}$ 1,2- and 1,4-addition, ${ }^{7}$ carboboration, ${ }^{8}$ and three-component coupling of carboncarbon multiple bonds, carbonyls, and arylboron reagents. ${ }^{9}$ It is worth noting that all the reactions utilise aryl- or 45 alkenylboron reagents and that few reports of alkylation reactions with alkylboron reagents have appeared. ${ }^{5}$ For instance, nickel-catalysed reaction of isoprene with benzaldehyde in the presence of triethylborane failed to afford the corresponding ethylated three-component coupling 50 product $\mathbf{1}$, and did result in reductive coupling yielding $\mathbf{2}$
(Scheme 1). ${ }^{10,11} \quad$ Fast $\beta$-hydride elimination from an ethylnickel intermediate $\mathbf{3}$ is inevitable, which renders the use of alkylboron reagents under nickel catalysis as alkylating agents difficult. During the last few years, we have 55 successfully developed simple yet unprecedented nickelcatalysed alkylation reactions with trialkylboranes, overcoming the competitive $\beta$-hydride elimination.

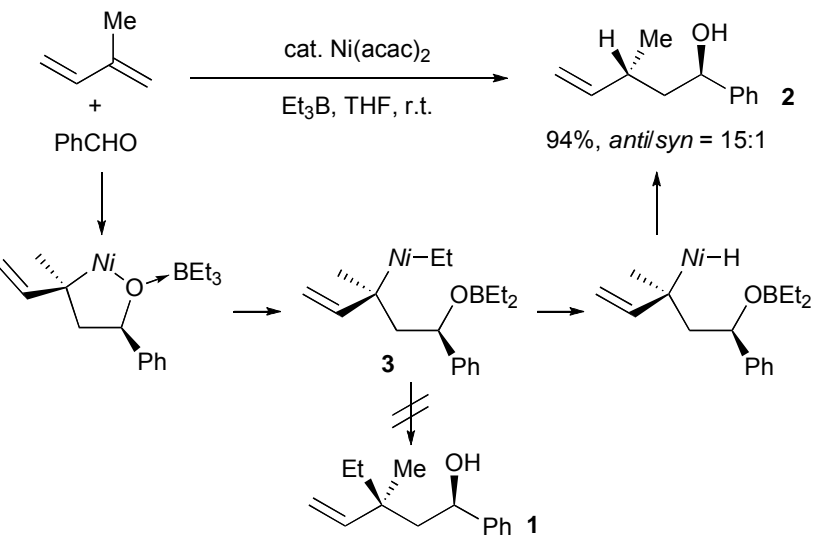

Scheme 1. Nickel-catalysed reductive coupling reaction with triethylborane

2.2 Nickel-catalysed alkylation of aldehydes with trialkylboranes

Alkylation of aldehydes with organometallic reagents is a ${ }_{65}$ basic and thus important reaction in organic chemistry. Conventional alkylboron reagents do not react with aldehydes, due to their modest reactivity. Based on reports of nickel catalysis for arylation of aldehyde with arylboron reagents ${ }^{7}$ as well as alkylations of aldehydes with dialkylzinc ${ }^{12}$ and 70 trialkylaluminum $^{13}$ reagents, we envisioned that a nickel catalyst can facilitate alkylation with alkylboron reagents. By suppressing undesirable $\beta$-hydride elimination from alkylnickel intermediates, we indeed developed such an alkylation reaction. 
Treatment of aldehydes with tri-n-butyl- or triethylborane in the presence of cesium carbonate and catalytic amounts of $\mathrm{Ni}(\mathrm{cod})_{2}$ and $\mathrm{P}(t-\mathrm{Bu})_{3}$ in toluene at room temperature for $24 \mathrm{~h}$ afforded the corresponding alkylated products in good yields 5 (Figure 1$).{ }^{14}$ A variety of aldehydes, including keto aldehyde, underwent the alkylation. The key for the successful alkylation is the combination of $\mathrm{P}(t-\mathrm{Bu})_{3}$ and cesium carbonate. Other ligands such as $\mathrm{PPh}_{3}, \mathrm{P}(n-\mathrm{Bu})_{3}$, and $\mathrm{P}(c-$ $\left.\mathrm{C}_{6} \mathrm{H}_{11}\right)_{3}$ were ineffective. In the absence of cesium carbonate 10 or with potassium carbonate instead of cesium carbonate, no butylated alcohols were obtained.

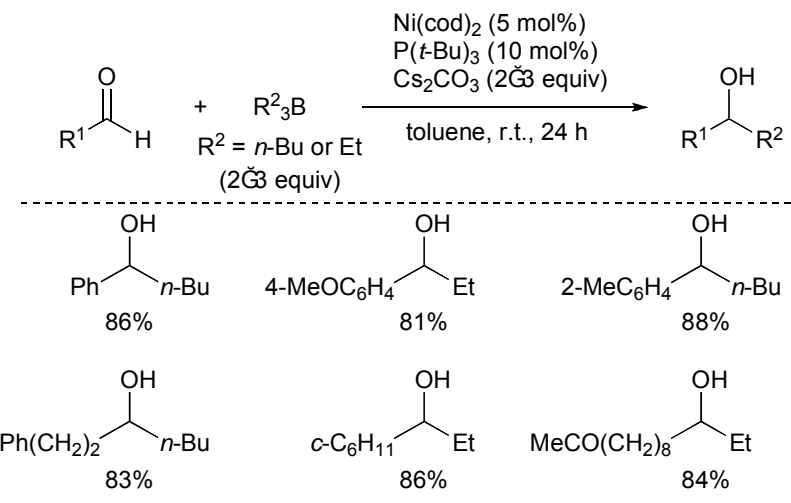

Fig 1. Nickel-catalysed alkylation of aldehydes

Trialkylboranes prepared by hydroboration from 15 hydroboranes and alkenes can be employed for the reaction (Scheme 2). Trihexylborane, prepared from borane-dimethyl sulfide complex and 1-hexene, reacted with benzaldehyde to afford 1-phenyl-1-heptanol in excellent yield. Alkylboranes, prepared from 9-borabicyclo[3.3.1]nonane (9-BBN) and 3,320 dimethyl-1-butene, transferred the 3,3-dimethyl-1-butyl group selectively.

$$
\begin{aligned}
& \overbrace{n-\mathrm{Bu}} \underset{\mathrm{THF}, 0 \mathrm{OC}, 3 \mathrm{~h}}{\stackrel{\mathrm{BH}_{3} ¥ \mathrm{SMe}_{2}}{\longrightarrow}}\left(n-\mathrm{C}_{6} \mathrm{H}_{13}\right)_{3} \mathrm{~B}
\end{aligned}
$$

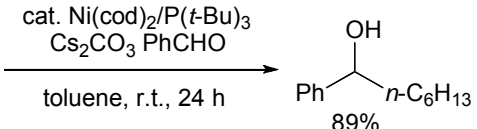
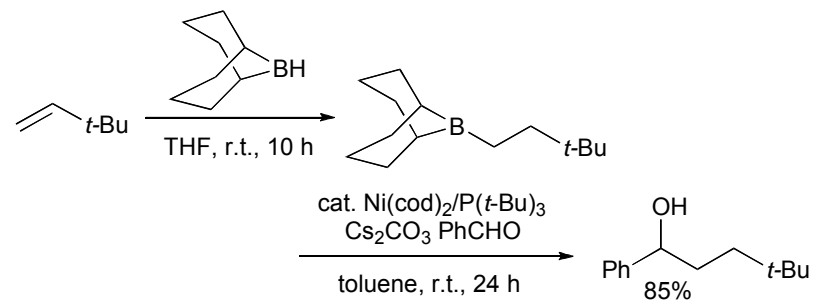

Scheme 2. Alkylations of aldehydes with alkylboranes prepared by hydroboration

25 Mechanistic work by Ogoshi ${ }^{15}$ on nickel $\left(\eta^{2}\right.$-aldehyde $)$ complexes promoted us to propose the following mechanism for the alkylation reaction (Scheme 3). A nickel(0) species initially reacts with aldehyde to generate a $\eta^{2}$-coordinated complex or its resonance form. Subsequent transmetalation 30 with trialkylborane or its borate formed by the action of cesium carbonate yields intermediate 4. $\mathrm{P}(t-\mathrm{Bu})_{3}$ highly promotes reductive elimination from $\mathbf{4}$ to provide the corresponding alcohol and the initial nickel complex. No primary alcohol $\mathrm{R}^{1} \mathrm{CH}_{2} \mathrm{OH}$ was detected, which would be 35 formed if $\beta$-hydride elimination from the intermediate $\mathbf{4}$ could occur. The exact role of cesium carbonate is not clear. Formation of a borate complex from $\mathrm{R}_{3}^{2} \mathrm{~B}$ and $\mathrm{Cs}_{2} \mathrm{CO}_{3}$ could facilitate the transmetalation step.

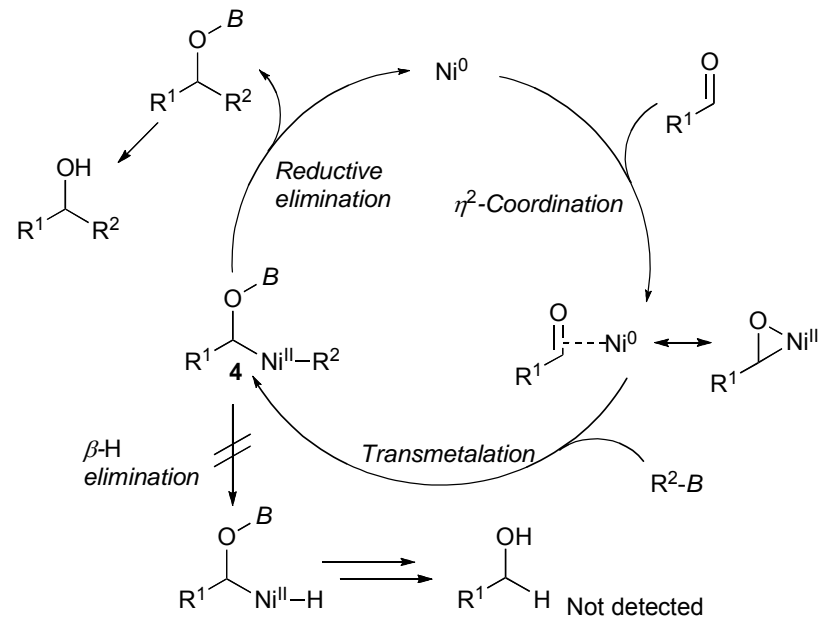

Scheme 3. Plausible mechanism for alkylation of aldehydes

Water is not only cheap, nontoxic, and nonflammable solvent but also offers extraordinary solvent effects on reactions performed in water. $^{16}$ The additions of organometallic reagents to aldehydes in aqueous media have 45 also been widely explored. ${ }^{17,18}$ However, alkylation of aldehydes in water is not a trivial reaction. We disclosed that nickel-catalysed alkylation reactions of aldehydes with trialkylboranes proceed smoothly in water (Table 1). ${ }^{19}$ Intriguingly, the reaction in water took place in the absence of 50 cesium carbonate (entries 1, 2, and 5), which is different from the alkylation in toluene. The amount of water also dramatically influenced the yield. An addition of 3 equiv of water in toluene had no effect (entry 3). The larger the amount of water was, the higher the yield was (entries 4-6).

55 Table 1. Butylation of benzaldehyde in water

\begin{tabular}{|c|c|c|c|}
\hline \multicolumn{2}{|c|}{$\begin{array}{c}\mathrm{PhCHO}+n-\mathrm{Bu}_{3} \mathrm{~B} \\
(0.50 \mathrm{mmol}) \quad(3 \text { equiv })\end{array}$} & $\begin{array}{l}\mathrm{Ni}(\mathrm{cod})_{2}(8 \mathrm{~mol} \%) \\
\mathrm{P}(t-\mathrm{Bu})_{3}(19 \mathrm{~mol} \%) \\
\text { additive } \\
\text { solvent, r.t., } 20 \mathrm{~h}\end{array}$ & $\overbrace{n-}^{\mathrm{OH}}$ \\
\hline entry & solvent & additive & yield \\
\hline 1 & toluene $(10 \mathrm{~mL})$ & none & $<2 \%$ \\
\hline 2 & toluene $(10 \mathrm{~mL})$ & $\mathrm{Cs}_{2} \mathrm{CO}_{3}$ (3 equiv) & $88 \%$ \\
\hline 3 & toluene (10 mL) & $\mathrm{H}_{2} \mathrm{O}$ (3 equiv) & $<2 \%$ \\
\hline 4 & water (5 mL) & none & $33 \%$ \\
\hline 5 & water $(10 \mathrm{~mL})$ & none & $63 \%$ \\
\hline 6 & water (20 mL) & none & $90 \%$ \\
\hline
\end{tabular}

It is worth noting that benzaldehyde, tri- $n$-butylborane, and the nickel catalyst were completely insoluble in water, and the 60 reaction proceeded in a biphasic system, organic droplets in water. The effect of water as a reaction medium is not clear. Water can enhance the $\eta^{2}$-coordination step and/or the transmetalation step. These steps cause the reduction of the 
total volume of the organic components, which water would enhance due to hydrophobic interaction. ${ }^{16,20}$ Moreover, an aqua complex $(n-\mathrm{Bu})_{3} \mathrm{~B} \cdot \mathrm{OH}_{2}$ can more readily undergo the transmetalation.

5 Scope of the alkylation in water was similar to that in toluene with the aid of cesium carbonate (Figure 1 and Scheme 2 vs. Scheme 4), although the yields obtained in water were generally lower.

$$
\begin{aligned}
& \mathrm{Et}_{\mathrm{H}}+\mathrm{Et}_{3} \mathrm{~B} \text { equiv) } \frac{\text { cat. Ni(cod) })_{2} / \mathrm{P}(t-\mathrm{Bu})_{3}}{\text { water }(20 \mathrm{~mL}), \text { r.t., } 20 \mathrm{~h}} \\
& \begin{array}{l}
\mathrm{R}=4-\mathrm{MeOC}_{6} \mathrm{H}_{4}, 59 \% ; \mathrm{R}=2-\mathrm{MeC}_{6} \mathrm{H}_{4}, 81 \% \\
\mathrm{R}=\mathrm{Ph}\left(\mathrm{CH}_{2}\right)_{2}, 69 \% ; \mathrm{R}=c-\mathrm{C}_{6} \mathrm{H}_{11}, 60 \%
\end{array}
\end{aligned}
$$

$$
\begin{aligned}
\mathrm{R} \underset{\mathrm{THF}, 0 \mathrm{CC}, 3 \mathrm{~h}}{\stackrel{\mathrm{BH}_{3} \# \mathrm{SMe}_{2}}{\longrightarrow}} & \left(\mathrm{RCH}_{2} \mathrm{CH}_{2}\right)_{3} \mathrm{~B} \\
& \stackrel{\text { cat. Ni(cod })_{2} / \mathrm{P}(t-\mathrm{Bu})_{3}}{\text { water }(20 \mathrm{~mL}) \text {, r.t., } 20 \mathrm{~h}}
\end{aligned}
$$$$
\mathrm{R}=n-\mathrm{Bu}, 74 \% ; \mathrm{R}=t-\mathrm{Bu}, 71 \% ; \mathrm{R}=\left(\mathrm{CH}_{2}\right)_{6} \mathrm{OSit}_{-\mathrm{BuMe}}, 69 \%
$$

Scheme 4. Nickel-catalysed alkylation with trialkylboranes in water

The reaction with trialkylborane having a benzyloxy moiety resulted in low yield (Scheme 5). To our delight, an addition of a catalytic amount of $\alpha$-cyclodextrin $(\alpha$-CD) dramatically improved the yield to $84 \%$. Additions of $\beta$-cyclodextrin ( $\beta$ $\left.{ }_{15} \mathrm{CD}\right)$ and $\gamma$-cyclodextrin $(\gamma$-CD) showed less efficiency. The exact role of $\alpha-C D$ is not clear. $\alpha-C D$ is known to accommodate a phenyl ring in its cavity most tightly among CDs. $^{21}$ We suppose that interaction between the benzyloxy group and the nickel or boron centre might suppress the 20 transmetalation step to result in low yield and that the inclusion of the benzyloxy group in $\alpha$-CD would help blocking out the unfavourable interaction.

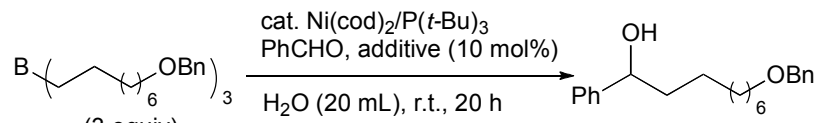

$$
\begin{aligned}
& \text { (3 equiv) } \\
& \begin{array}{r|rrrr}
\text { additive } & \text { none } & \alpha-\mathrm{CD} & \beta-\mathrm{CD} & \gamma-\mathrm{CD} \\
\hline \text { yield } & 24 \% & 84 \% & 37 \% & <2 \%
\end{array}
\end{aligned}
$$

Scheme 5. Effect of cyclodextrins in nickel-catalysed alkylation in water

\subsection{Nickel-catalysed 1,4-addition of trialkylboranes to $\alpha, \beta$ - unsaturated esters}

Transition-metal-catalysed 1,4-addition of alkylmetals is among the most powerful and promising $\mathrm{C}-\mathrm{C}$ bond formations 30 in organic synthesis. In particular, copper-catalysed addition of alkylmagnesium, alkylzinc, and alkylaluminum reagents have been widely studied and accomplished asymmetric induction using a variety of chiral ligands. ${ }^{22}$ 1,4-Addition reactions with trialkylboranes have been less explored, ${ }^{23}$ 35 although 1,4-addition of aryl- and alkenylboronic acid derivatives under rhodium, ${ }^{3}$ palladium, ${ }^{24}$ and nickel ${ }^{7}$ catalysis has been established.

On the basis of results obtained in the previous section, we have developed nickel-catalysed 1,4-addition of
${ }_{40}$ trialkylboranes to $\alpha, \beta$-unsaturated esters (Figure 2) ${ }^{25}$ Treatment of benzyl crotonate with triethylborane in the presence of a $\mathrm{Ni}(\mathrm{cod})_{2} / \mathrm{P}(t-\mathrm{Bu})_{3}$ catalyst and cesium carbonate in toluene at room temperature for $17 \mathrm{~h}$ afforded the 1,4adduct $5 \mathbf{a}$ in $88 \%$ yield. The addition of cesium carbonate 45 was essential to attain satisfactory yield. The chlorobenzyl moiety of $\mathbf{5 d}$ remained untouched, and the conceivable Suzuki-Miyaura cross-coupling product was not obtained. Not only crotonic acid esters but also unsaturated esters having a larger alkyl group at the $\beta$ position participated in the 50 reaction. For instance, cyclohexyl-substituted esters 5c was obtained in $81 \%$ yield. Methoxy-substituted cinnamate ester also reacted to yield $\mathbf{5 e}$ in $57 \%$ yield.

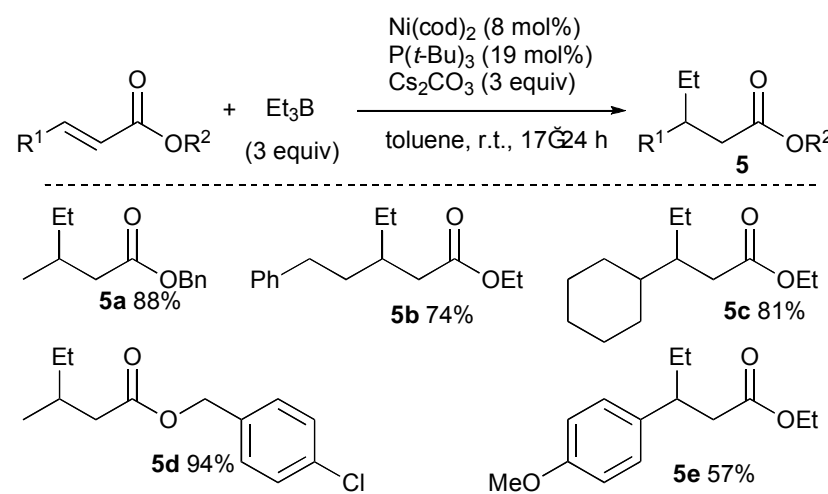

Fig 2. Nickel-catalysed 1,4-addition of triethylborane

55 1,4-Addition of triethylborane to benzyl acrylate is a challenging because acrylate can undergo radical and anionic polymerisation much more readily. 1,4-Adduct 6 was indeed obtained in only 59\% yield under similar conditions (Scheme 6). About half of the starting ester underwent the undesired ${ }_{60}$ polymerisation. The addition of the initially formed boryl enolate to acrylate ester would cause the side reaction. Considering that smooth protonolysis of the intermediate was essential, we performed the reaction in an aqueous/organic biphasic system. ${ }^{26}$ To our delight, the desired product 6 was ${ }_{65}$ obtained in $94 \%$ yield under water/ $\mathrm{Et}_{2} \mathrm{O}$ biphasic conditions.

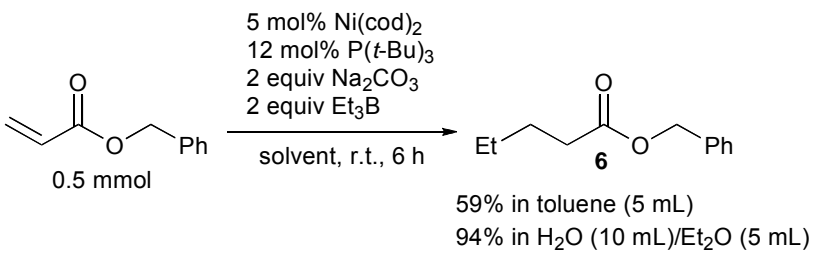

Scheme 6. 1,4-Addition to acrylate ester in water/ether biphasic solvent

Initial attempts to perform sequential hydroboration/1,4addition resulted in failure (Scheme 7). No 1,4-addition took 70 place, and the starting material was completely recovered. After many experiments, we finally found that an addition of 4.0 equiv of methanol dramatically enhanced the reaction. Interestingly, a large amount of methanol prevented the reaction completely. Other alcohols such as tert-butyl alcohol 75 and phenol had no influence on yield. The use of $\mathrm{N}, \mathrm{N}$ dimethylacetamide (DMA) and water led to slight improvement of the yield. A much stronger Lewis base, pyridine, did not work to promote the reaction. 

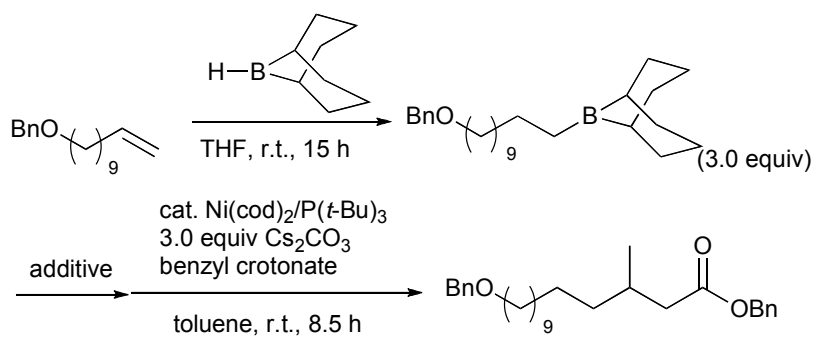

\begin{tabular}{c|cccc} 
additive & none & methanol (4 equiv) & water (4 equiv) & DMA (4 equiv) \\
\hline yield & $0 \%$ & $96 \%$ & $24 \%$ & $65 \%$
\end{tabular}

Scheme 7. Effect of additive in sequential hydroboration/nickel-catalysed 1,4-addition

With the optimal methanol-promoted conditions, 1,45 addition of several 9-alkyl-9-BBN to benzyl crotonate was examined (Figure 3). The advantage of the reaction is facile introduction of functionalised alkyl groups. For instance, alkylborane having an $s p^{3} \mathrm{C}-\mathrm{Br}$ bond, which the corresponding alkylmagnesium halide and dialkylzinc are 10 difficult to prepare, underwent 1,4-addition smoothly.

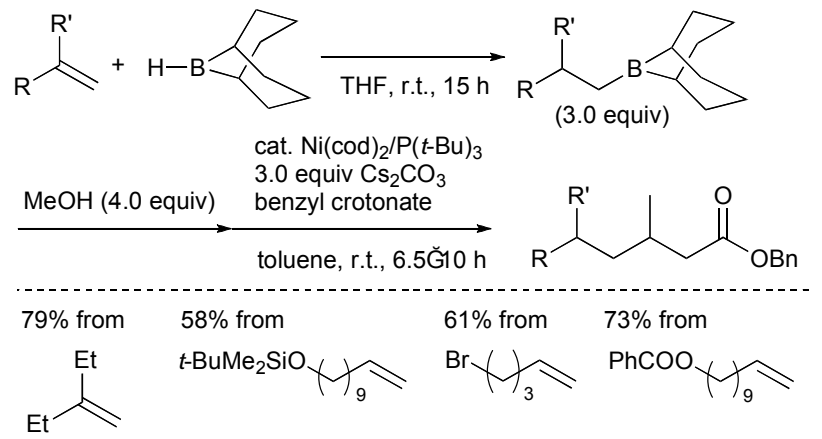

Fig. 3. Methanol-promoted nickel-catalysed 1,4-addition of functionalised alkylborane reagents

We are tempted to assume the mechanism of the reaction 15 with 9-alkyl-9-BBN as follows (Scheme 8). Formation of a nickel $\left(\eta^{2}\right.$-alkene) complex initially took place. Coordination of the carbonyl moiety of 7 to alkylborane affords the intermediate 8 and then $\eta^{3}$-coordinated complex $9 .{ }^{27}$ Transfer of the $\mathrm{R}$ group on the boron to nickel furnishes an alkylnickel 20 species 10. Finally, reductive elimination from $\mathbf{1 0}$ affords $\mathbf{1 1}$ and regenerates the initial nickel complex. Protonolysis of $\mathbf{1 1}$ would provide the product. The exact roles of cesium carbonate and methanol are not clear at this stage. They can enhance the transmetalation step through their coordination to

25 the boron centre of $\mathbf{9}$. Moreover, methanol can be a good proton source for intermediate $\mathbf{1 1 .}$

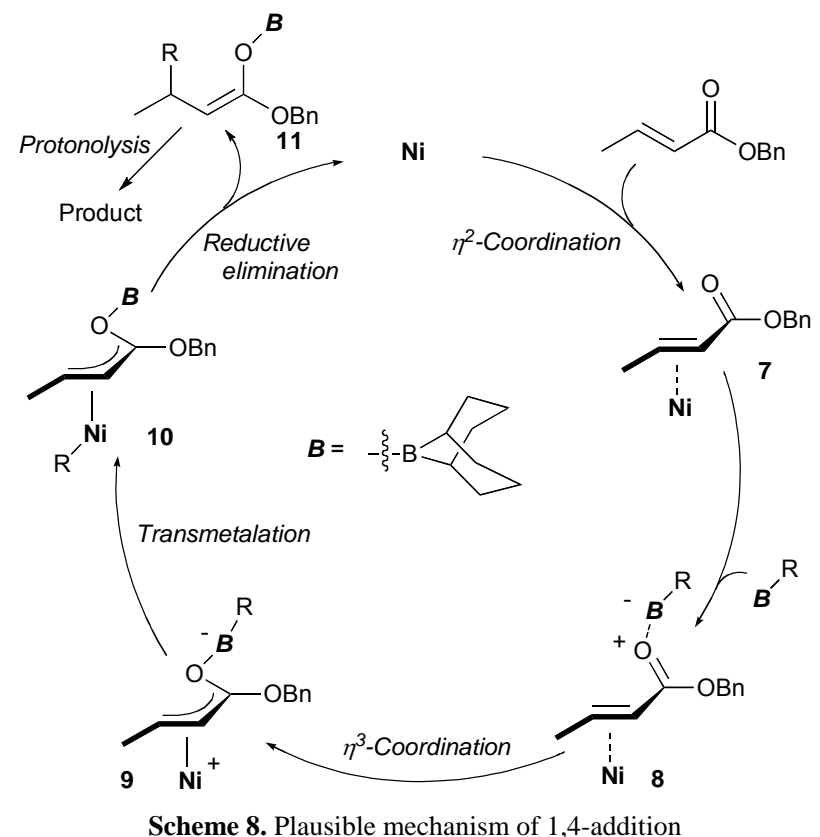

\section{${ }_{30} 2.4$ Nickel-catalysed 1,4-addition of bis(pinacolato)diboron to $\alpha, \beta$-unsaturated esters}

Platinum-, rhodium-, and copper-catalysed 1,4-additions of diborons to $\alpha, \beta$-unsaturated aldehydes and ketones are important procedures for the preparation of organoboranes 35 having carbonyl functionalities at the $\beta$ position. ${ }^{28}$ However, similar additions to $\alpha, \beta$-unsaturated esters and amides have been still challenging. Moreover, the reaction of sterically demanding multisubstituted esters and amides is not trivial. Considering the similarity in the Lewis acidic character 40 between trialkylboranes $\left(\mathrm{R}-\mathrm{BR}_{2}\right)$ and bis(pinacolato)diboron $[($ pin)B-B(pin), pin = pinacolato $]$, we expected that the nickel-catalysed conditions developed in the previous section would be applicable to 1,4-addition of bis(pinacolato)diboron to $\alpha, \beta$-unsaturated esters.

45 This was indeed the case, and after screening reaction conditions, we realised efficient borations of a wide range of $\alpha, \beta$-unsaturated esters and amides (Figure 4). ${ }^{29}$ The substitution patterns of the substrates had little influence on reaction efficiency. tert-Alkyl-substituted pinacolatoborons 50 were obtained in high yields. A plausible reaction mechanism would be similar to that described in Scheme 8 . 


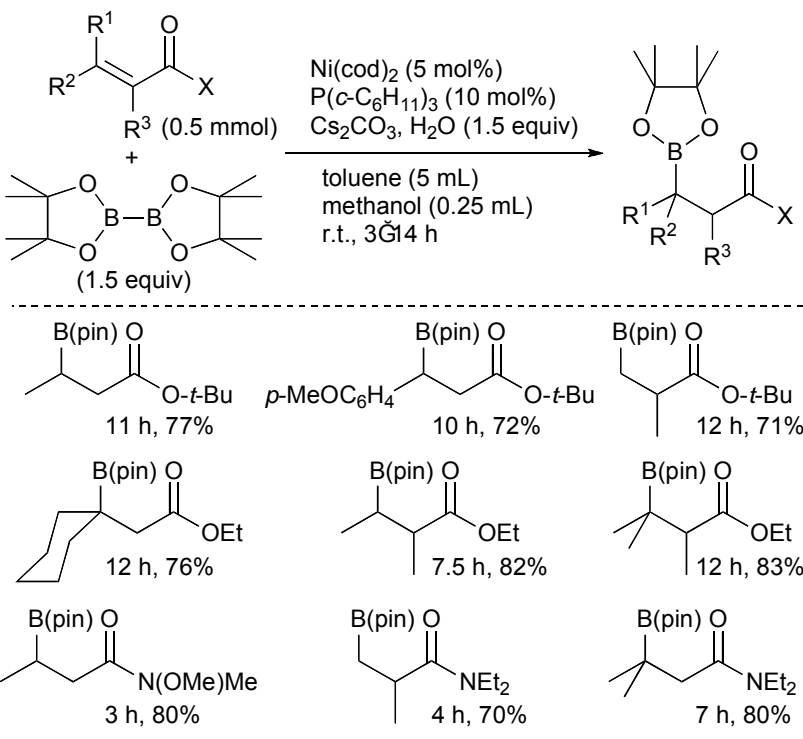

Figure 4. $\beta$-Boration of $\alpha, \beta$-unsaturated esters and amides

\section{Nickel-catalysed reactions with silacyclobutanes}

\section{3.1 Overview of silacyclobutanes under transition metal} catalysis

Organosilicon compounds have generally high thermal and chemical stabilities, compared to other organometallic reagents. Especially, tetraalkylsilanes are quite stable and 10 inert to water and oxygen. Their low reactivity often becomes problematic from the synthetic point of view. However, silacyclobutanes have quite interesting reactivity based on their ring strain and high Lewis acidity, and thus are useful in organic synthesis. ${ }^{30}$

15 Platinum- and palladium-catalysed transformations of silacyclobutanes are well known, and usually begin with oxidative addition of silacyclobutanes to low valent transition metals. $^{31,32}$ In contrast, nickel-catalysed reactions of silacyclobutanes have not been explored, although nickel 20 belongs to the same group, group 10 . Considering the Lewis acidity of silacyclobutanes that is comparable to that of trialkylboranes, we started to develop nickel-catalysed reactions of silacyclobutanes with carbonyl compounds.

\subsection{Nickel-catalysed reactions of silacyclobutanes with aldehydes}

Treatment of 1,1-dimethylsilacyclobutane with benzaldehyde in the presence of catalytic amounts of $\mathrm{Ni}(\mathrm{cod})_{2}$ and $\mathrm{PPh}_{2} \mathrm{Me}$ in toluene at $100{ }^{\circ} \mathrm{C}$ afforded allylbenzyloxydimethylsilane in 30 high yield (Table 2, entry 1). ${ }^{33}$ Ester functionality could survive under the reaction conditions (entry 3). Aliphatic aldehydes as well as aromatic aldehydes were converted to alkoxyallylsilanes (entries 4 and 5). In the reaction of transcinnamaldehyde, 1,2-reduction predominated to afford the 35 corresponding allylcinnamyloxysilane as the sole product (entry 6).
Table 2. Nickel-catalysed reaction of silacyclobutane with aldehydes

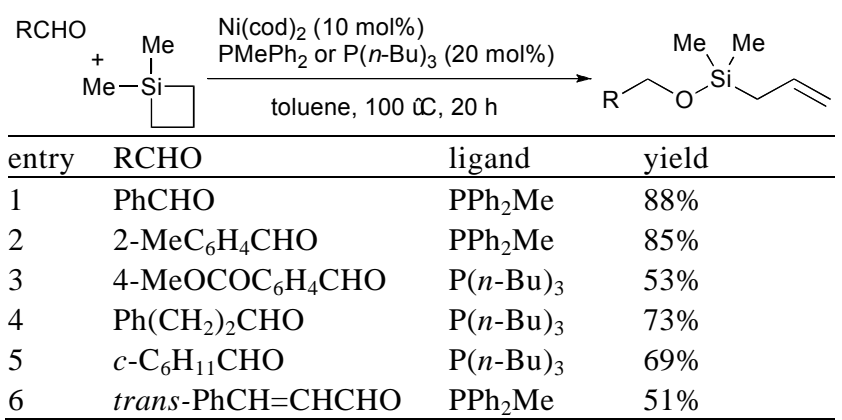

40 Apparently, nickel-catalysed carbon-silicon bond cleavage is involved in this transformation. In analogy with the mechanism in Scheme 3, we propose the following mechanism (Scheme 9). A nickel(0) species initially reacts with aldehyde to generate $\eta^{2}$-coordinated complex or its 45 resonance form. Subsequent transmetalation with silacyclobutane gives the intermediate 12. Following $\beta$ hydride elimination and reductive elimination furnish allyl(alkoxy)silane and regenerate the initial low valent nickel (Path A). Direct reductive elimination (Path B) is much s0 slower than $\beta$-hydride elimination.

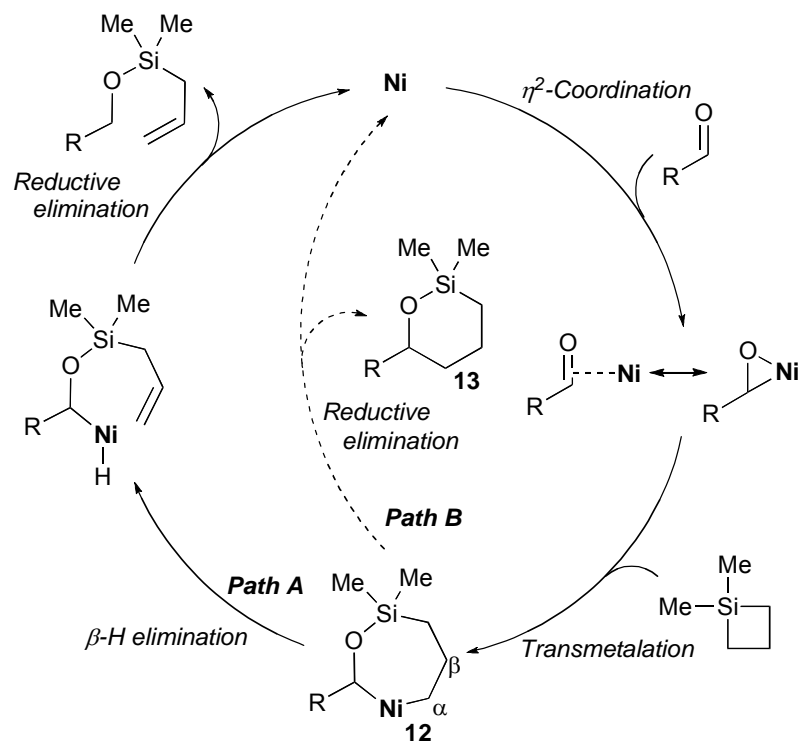

Scheme 9. Plausible mechanism of the reaction of silacyclobutane with aldehydes

If the intermediate $\mathbf{1 2}$ had no hydrogens at the $\beta$-position, 55 reductive elimination could proceed to afford the ringexpanded product like 13 (Path B). As expected, benzosilacyclobutene $\mathbf{1 4}$ reacted with benzaldehyde under similar conditions to afford benzoxasilacyclohexene $\mathbf{1 5}$ in good yield (Scheme 10). Interestingly, regioselective 60 cleavage of the $s p^{2}$ carbon-silicon bond occurred. TamaoFleming oxidation could transform 14 to the corresponding diol. The overall transformation is equivalent to 2(hydroxymethyl)phenylation of aldehydes. 


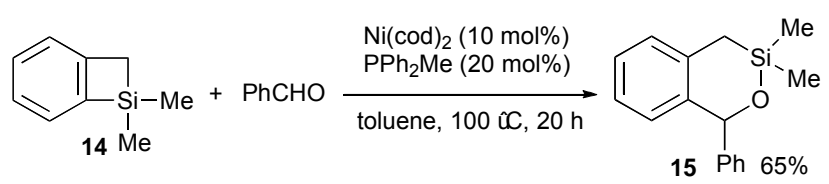

$\underset{\mathrm{MeOH} / \mathrm{THF}=1: 1 \text {, r.t., } 24 \mathrm{~h}}{\mathrm{KFHCO}}{ }_{3}$, aq $\mathrm{H}_{2} \mathrm{O}_{2}$

Scheme 10. Nickel-catalysed ring-expansion

3.3 Nickel-catalysed regio- and stereoselective silylation of 5 terminal alkenes with silacyclobutanes for the synthesis of vinylsilanes from alkenes

Vinylsilanes are very useful organometallic reagents. Methods for the synthesis of vinylsilanes are thus extensively studied. Regio- and stereoselective direct silylation of 10 alkenes is an ideal route to vinylsilanes. Transition-metalcatalysed dehydrogenative silylation of alkenes with hydrosilanes sounds attractive (Scheme 11). ${ }^{34}$ However, the substrates were limited to activated alkenes such as $\alpha, \beta$ unsaturated esters and styrenes. Moreover, the 15 dehydrogenative silylations required a large excess of alkenes because the alkenes were hydrogen acceptors as well as substrates to be silylated. During the investigation of nickelcatalysed reactions of silacyclobutanes with aldehydes, we found nickel-catalysed silylation of alkenes with 20 silacyclobutanes. $^{35}$ The reaciton provides a facile and straightforward access to vinylsilanes from a variety of terminal alkenes without formation of byproducts such as alkanes.

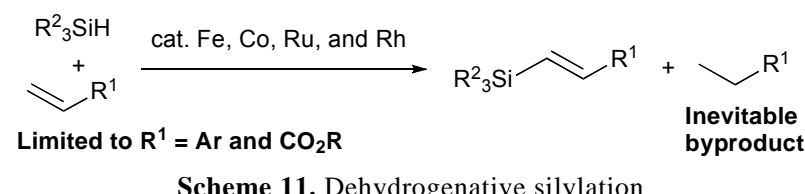

Table 3 displays the broad scope of the silylation reaction with silacyclobutane. Except for the silylation of acrylamide (entry 2), the reactions proceeded in high yields with exclusive $E$ selectivity. Not only acrylates, acrylamide, and 30 styrenes (entries 1-6) but also unactivated alkenes such as 1tetradecene were efficiently silylated (entries 7-10). Functional groups such as pyridyl, ester, and silyl ether were compatible under the reaction conditions.

Notably, benzosilacyclobutene $\mathbf{1 4}$ was also the suitable 35 silylating agent (Equation 1). Styrene reacted with 14 to furnish the benzyldimethylsilyl-substituted styrene regio- and stereoselectively. In this case, $\mathrm{Ni}(\mathrm{cod})_{2} / 2 \mathrm{PPh}_{3}$ catalyst gave the better result. The palladium-catalysed cross-coupling reaction of benzyl-substitued vinylsilane with aryl halides ${ }^{36}$ 40 would be applicable to the product.

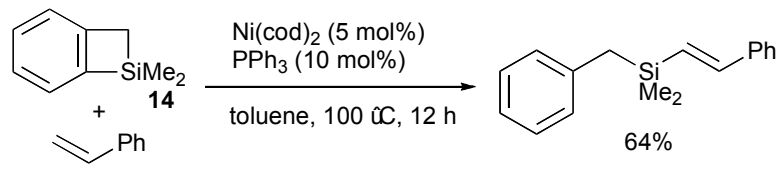

Table 3. Nickel-catalysed silylation of terminal alkenes with silacyclobutane

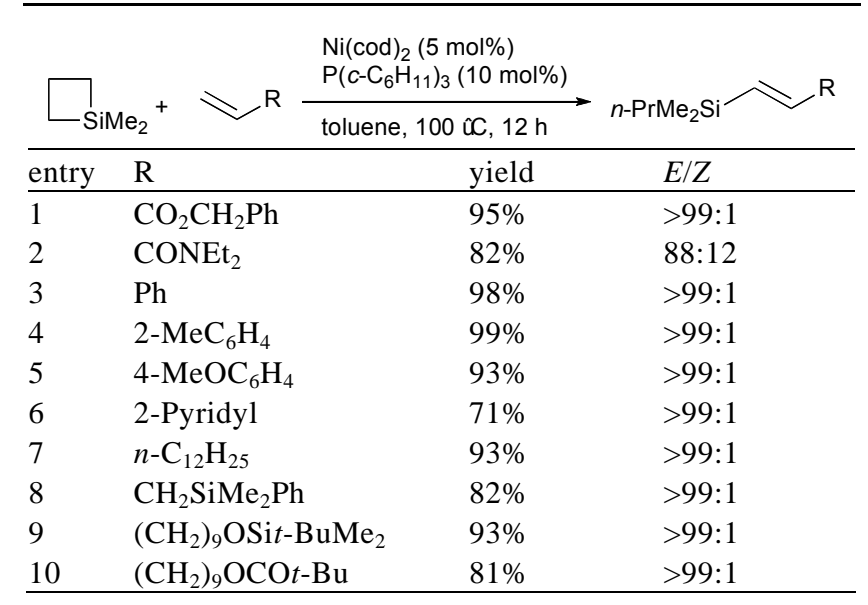

The reaction would proceed as follows (Scheme 12). Oxidative addition of silacyclobutanes to zerovalent nickel followed by insertion of alkene to the $\mathrm{Si}-\mathrm{Ni}$ bond of the intermediate affords nickelasilacycloheptane 16. In the case 50 of benzosilacyclobutane 14, the oxidative addition of the $s p^{2} \mathrm{C}-\mathrm{Si}$ bond to $\mathrm{Ni}(0)$ predominates over that of the benzylic $s p^{3} \mathrm{C}-\mathrm{Si}$ bond. Subsequent $\beta$-H elimination followed by reductive elimination produces product to complete the catalytic cycle. The result of the silylation of terminally ${ }_{55}$ deuterated styrene was consistent with our plausible mechanism (Equation 2).

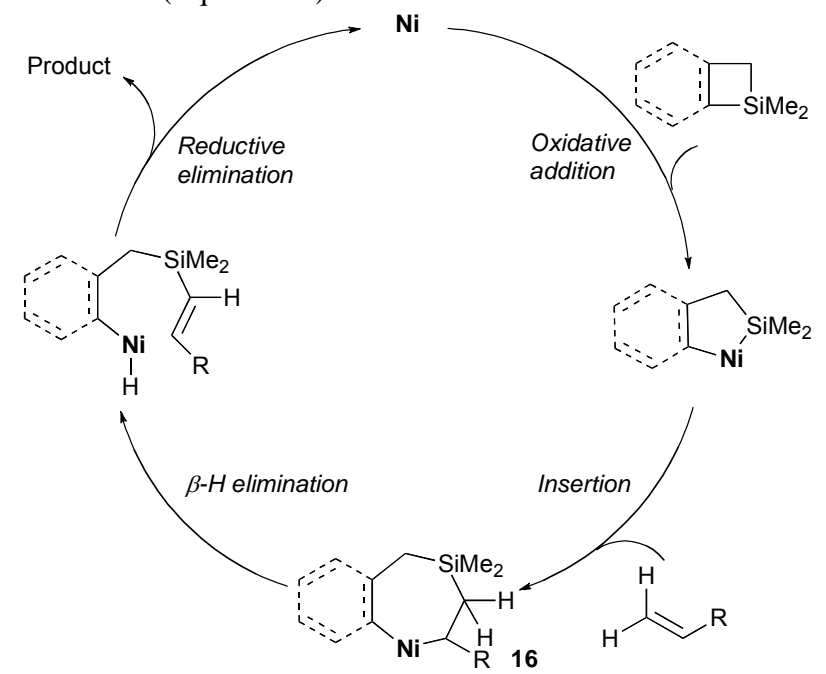

Scheme 12. Plausible mechanism of nickel-catalysed silylation of alkenes

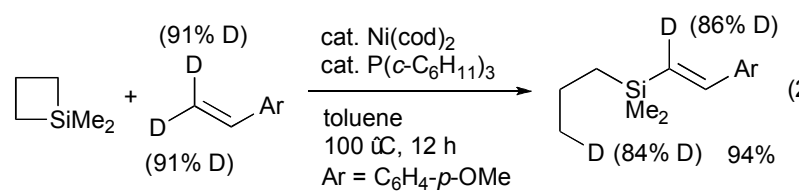

\section{Conclusions}

We have focused on the reactivity of electron-rich low valent nickel complexes and succeeded in the activation of trialkylboranes, diboron, and silacyclobutanes by the nickel 
catalysts. The new modes of activation enabled several synthetically useful reactions with these reagents for carboncarbon, -boron, and -silicon bond formations, which exhibited the interesting nature of the nickel complexes. ${ }_{5}$ Detailed mechanistic studies and further applications including asymmetric reactions are awaited.

\section{Acknowledgment}

This work was supported by Grants-in-Aid for Scientific Research, COE Research, Global COE Research from MEXT 10 and JSPS. K.H. acknowledges JSPS for financial support.

\section{Notes and references}

1 Modern Organonickel Chemistry; Y. Tamaru, Ed., Wiley-VCH, Weinheim, 2005; R. M. Moslin, K. Miller-Moslin, T. F. Jamison, Chem. Commun., 2007, 4441-4449; S. Ikeda, Acc. Chem. Res., 2000,

15 33, 511-519; J. Montgomery, Acc. Chem. Res., 2000, 33, 467-473; T. F. Jamison, Tetrahedron, 2006, 62, 7503.

2 N. Miyaura and A. Suzuki, Chem. Rev., 1995, 95, 2457-2483.

3 K. Fagnou and M. Lautens, Chem. Rev., 2003, 103, 169-196; T. Hayashi and K. Yamasaki, Chem. Rev., 2003, 103, 2829-2844.

204 V. Percec, J.-Y. Bae, and D. H. Hill, J. Org. Chem., 1995, 60, 10601065; M. Ueda, A. Saitoh, S. Oh-tani, and N. Miyaura, Tetrahedron, 1998, 54, 13709-13086; D. Zim, V. R. Lando, J. Dupont, and A. L. Monterio, Org. Lett., 2001, 3, 3049-3051; Z.-Y. Tang and Q.-S. Hu, J. Am. Chem. Soc., 2004, 126, 3058-3059.

255 J. Zhou and G. C. Fu, J. Am. Chem. Soc., 2004, 126, 1340-1341; F. Gonzalez-Bobes and G. C. Fu, J. Am. Chem. Soc., 2006, 128, 5360 5361; B. Saito and G. C. Fu, J. Am. Chem. Soc., 2007, 129, 9602 9603.

6 Y. Kobayashi and E. Ikeda, J. Chem. Soc., Chem. Commun., 1994

30 1789-1790; H. Chen and M.-Z. Deng, J. Organomet. Chem., 2000 603, 189-193; Y. Kobayashi, R. Mizojiri, and E. Ikeda, Synlett, 1995, 571-572; Y. Kobayashi, Y. Tokoro, and K. Watatani, Eur. J. Org. Chem., 2000, 3825-3834.

7 G. Takahashi, E. Shirakawa, T. Tsuchimoto, and Y. Kawakami, Chem. Commun., 2005, 1459-1460; E. Shirakawa, Y. Yasuhara, and T. Hayashi, Chem. Lett., 2006, 35, 768-769; T. Arao, K. Kondo, and T. Aoyama, Tetrahedron Lett., 2007, 48, 4115-4117.

8 E. Shirakawa, G. Takahashi, T. Tsuchimoto, and Y. Kawakami, Chem. Commun., 2002, 2210-2211; G. Takahashi, E. Shirakawa, T. Tsuchimoto, and Y. Kawakami, Adv. Synth. Catal., 2006, 348, 837840; M. Suginome, A. Yamamoto, and M. Murakami, J. Am. Chem Soc., 2003, 125, 6358-6359; M. Suginome, M. Shirakura, and A. Yamamoto, J. Am. Chem. Soc., 2006, 128, 14438-14439.

9 M. Kimura, S. Matsuo, K. Shibata, and Y. Tamaru, Angew. Chem.,

45 Int. Ed., 1999, 38, 3386-3388; M. Kimura, K. Shibata, Y. Kobayashi, and Y. Tamaru, Tetrahedron Lett., 2000, 41, 6789-6793; K. Shibata, M. Kimura, K. Kojima, S. Tanaka, and Y. Tamaru, J. Organomet. Chem., 2001, 624, 348-353; S. J. Patel and T. F. Jamison, Angew. Chem., Int. Ed., 2003, 42, 1364-1367; S. J. Patel and T. F. Jamison,

50 Angew. Chem., Int. Ed., 2004, 43, 3941-3944; T. T. Jayanth, and C.H. Cheng, Angew. Chem., Int. Ed., 2007, 46, 5921-5924.

10 M. Kimura, A. Ezoe, K. Shibata, and Y. Tamaru, J. Am. Chem. Soc., 1998, 120, 4033-4034; M. Kimura and Y. Tamaru, Top. Curr. Chem., 2007, 279, 173-207.

5511 Other reductive coupling reactions that employ trialkylboranes as reducing agents. Y. Sato, M. Takimoto, and M. Mori, Tetrahedron Lett., 1996, 37, 887-890; W.-S. Huang, J. Chan, and T. F. Jamison, Org. Lett., 2000, 2, 4221-4223; M. Kimura, A. Ezoe, S. Tanaka, and Y. Tamaru, Angew. Chem., Int. Ed., 2001, 40, 3600-3602; K. M.

60 Miller, W.-S. Huang, and T. F. Jamison, J. Am. Chem. Soc., 2003, 125, 3442-3443; T. Luanphaisarnnont, C. O. Ndubaku, and T. F. Jamison, Org. Lett., 2005, 7, 2937-2940; K. M. Miller and T. F. Jamison, Org. Lett., 2005, 7, 3077-3080; A. Herath and J. Montgomery, J. Am. Chem. Soc., 2006, 128, 14030-14031; A.
65 Herath, B. B. Thompson, and J. Montgomery, J. Am. Chem. Soc., 2007, 129, 8712-8713.

12 M. I. Burguete, M. Collado, J. Escorihuela, F. Galindo, E. Garcíaverdugo, S. V. Luis, and M. J. Vicent, Tetrahedron Lett., 2003, 44, 6891-6894.

7013 T. Ichiyanagi, S. Kuniyama, M. Shimizu, and T. Fujisawa, Chem. Lett., 1998, 1033-1034; K. Biswas, O. Prieto, P. J. Goldsmith, and S. Woodward, Angew. Chem., Int. Ed., 2005, 44, 2232-2234.

14 K. Hirano, H. Yorimitsu, and K. Oshima, Org. Lett., 2005, 7, 46894691.

7515 S. Ogoshi, M. Oka, and H. Kurosawa, H. J. Am. Chem. Soc., 2004, 126, 11802-11803.

16 C.-J. Li and T.-H. Chan, Organic Reactions in Aqueous Media, John Wiley \& Sons, New York, 1997; P. A. Grieco, Organic Synthesis in Water, Blackie Academic \& Professional, London, 1998; A.

$80 \quad$ Lubineau and J. Auge, Modern Solvents in Organic Synthesis, P. Knochel, Ed., Springer-Verlag, Berlin/Heidelberg 1999.

17 Allylation with allylmetals: J. Nokami, J. Otera, T. Sudo, and R. Okawara, Organometallics, 1983, 2, 191-193; C. Petrier and J. L. Luche, J. Org. Chem., 1985, 50, 910-912; C.-J. Li and T.-H. Chan,

85 Tetrahedron Lett., 1991, 32, 7017-7020; M. Sugiura, K. Hirano, and S. Kobayashi, J. Am. Chem. Soc., 2004, 126, 7182-7183; T. Tsuji, S. Usugi, H. Yorimitsu, H. Shinokubo, S. Matsubara, and K. Oshima, Chem. Lett., 2002, 2-3 and references cited therein.

18 Catalytic arylation or alkenylation with organoboronic acid derivatives: References 3 and 7.

19 K. Hirano, H. Yorimitsu, and K. Oshima, Adv. Synth. Catal., 2006, 348, 1543-1546.

20 H. Yorimitsu, T. Nakamura, H. Shinokubo, K. Oshima, K. Omoto, and H. Fujimoto, J. Am. Chem. Soc., 2000, 122, 11041-11047; H. Yorimitsu, H. Shinokubo, S. Matsubara, K. Oshima, K. Omoto, and H. Fujimoto, J. Org. Chem., 2001, 66, 7776-7785; H. Kinoshita, T. Nakamura, H. Kakiya, H. Shinokubo, S. Matsubara, and K. Oshima, Org. Lett., 2001, 3, 2521-2524.

21 F. Hapiot, S. Tilloy, and E. Monflier, Chem. Rev., 2006, 106, 767781.

22 A. Alexakis and C. Benhaim, Eur. J. Org. Chem., 2002, 3221-3236; B. E. Rossiter and N. M. Swingle, Chem. Rev., 1992, 92, 771-806; S. Woodward, Angew. Chem., Int. Ed., 2005, 44, 5560-5562.

23 There are a few examples of the 1,4-additions of trialkylboranes to $\alpha, \beta$-unsaturated aldehydes and ketones under radical conditions. However, the radical conditions are not applicable to the addition to $\alpha, \beta$-unsaturated esters because they are prone to undergo radical polymerisation. H. C. Brown and G. W. Kabalka, J. Am. Chem. Soc., 1970, 92, 714-716.

11024 C.-S. Cho, S. Motofusa, K. Ohe, and S. Uemura, J. Org. Chem., 1995, 60, 883-888; T. Nishikata, Y. Yamamoto, and N. Miyaura, Angew. Chem., Int. Ed., 2003, 42, 2768-2770; T. Nishikata, Y. Yamamoto, and N. Miyaura, Organometallics, 2004, 23, 4317-4324; X. Lu and S. Lin, J. Org. Chem., 2005, 70, 9651-9653; F. Gini, B. Hessen, and A. J. Minnaard, Org. Lett., 2005, 7, 5309-5312; T. Yamamoto, M. Iizuka, T. Ohta, and Y. Itoh, Chem. Lett., 2006, 35, 198-199; P. He, Y. Lu, C.-G. Dong, and Q.-S. Hu, Org. Lett., 2007, 9, 343-346.

25 K. Hirano, H. Yorimitsu, and K. Oshima, Org. Lett., 2007, 9, 15411544.

12026 H. Kinoshita, H. Shinokubo, and K. Oshima, J. Am. Chem. Soc., 2003, 125, 7784-7785.

27 S. Ogoshi, T. Yoshida, T. Nishida, M. Morita, and H. Kurosawa, J. Am. Chem. Soc., 2001, 123, 1944-1950; J. A. Marshall, M. Herold, H. S. Eidam, and P. Eidam, Org. Lett., 2006, 8, 5505-5508; B. A. Grisso, J. R. Johson, and P. B. Mackenzie, J. Am. Chem. Soc., 1992, 114, 5160-5165; S. Ikeda and Y. Sato, J. Am. Chem. Soc., 1994, 116, 5975-5976.

28 N. J. Bell, A. J. Cox, N. R. Cameron, J. S. O. Evans, T. B. Marder, M. A. Duin, C. J. Elsevier, X. Baucherel, A. A. D. Tulloch, and R. P. Tooze, Chem. Commun., 2004, 1854-1855; G. W. Kabalka, B. C. Das, and S. Das, Tetrahedron Lett., 2002, 43, 2323-2325; H. Ito, H. Yamanaka, J. Tateiwa, and A. Hosomi, Tetrahedron Lett., 2000, 41, 6821-6825; K. Takahashi, T. Ishiyama, and N. Miyaura, J. Organomet. Chem., 2001, 625, 47-53; S. Mun, J. E. Lee, and J. Yun, Org. Lett., 2006, 8, 4887-4889. 
29 K. Hirano, H. Yorimitsu, and K. Oshima, Org. Lett., 2007, 9, 50315033.

30 K. Hirano, H. Yorimitsu, and K. Oshima, In Electronic Encyclopedia of Reagents for Organic Synthesis, L. A. Paquette, P. L. Fuchs, D.

$5 \quad$ Crich, and G. A. Molander, Eds.; John Wiley and Sons: 2008, in press, DOI: 10.1002/047084289X.rn00813; J. Hermanns and B. Schmidt, J. Chem. Soc., Perkin Trans. 1, 1998, 2209-2230.

31 D. R. Weyneberg and L. E. Nelson, J. Org. Chem., 1965, 30, 26182621; H. Yamashita, M. Tanaka, and K. Honda, J. Am. Chem. Soc., 1995, 117, 8873-8874.

32 H. Sakurai and T. Imai, Chem. Lett., 1975, 891-894; Y. Takeyama, K. Nozaki, K. Matsumoto, K. Oshima, and K. Utimoto, Bull. Chem. Soc. Jpn., 1991, 64, 1461-1466; T. Tanaka, H. Yamashita, S. Shimada, and M. Tanaka, Organometallics, 1997, 16, 3246-3248; Y. Tanaka,

15 H. Yamashita, and M. Tanaka, Organometallics, 1996, 15, 1524 1526; Y. Tanaka and M. Yamashita, Appl. Organomet. Chem., 2002, 16, 51-54; B. P. S. Chauhan, Y. Tanaka, H. Yamashita, and M. Tanaka, Chem. Commun., 1996, 1207-1208; Y. Tanaka, A. Nishigaki, Y. Kimura, and M. Yamashita, Appl. Organomet. Chem., 2001, 15, 667-670; N. P. Reddy, T. Hayashi, and M. Tanaka, Chem. Commun., 1996, 1865-1866.

33 K. Hirano, H. Yorimitsu, and K. Oshima, Org. Lett., 2006, 8, 483485.

34 F. Kakiuchi, Y. Tanaka, N. Chatani, and S. Murai, J. Organomet.

$25 \quad$ Chem., 1993, 456, 45-47; Y. Seki, K. Takeshita, K. Kawamoto, S. Murai, and N. Sonoda, Angew. Chem., Int. Ed. Engl. 1980, 19, 928; K. Takeshita, Y. Seki, K. Kawamoto, S. Murai, and N. Sonoda, J. Org. Chem., 1987, 52, 4864-4868; F. Kakiuchi, K. Nogami, N. Chatani, Y. Seki, and S. Murai, Organometallics, 1993, 12, 474830 4750; R. Takeuchi and H. Yasue, Organometallics, 1996, 15, 20982102.

35 K. Hirano, H. Yorimitsu, and K. Oshima, J. Am. Chem. Soc., 2007, 129, 6094-6095.

36 S. E. Denmark and S. A. Tymonko, J. Am. Chem. Soc., 2005, 127, 8004-8005.

Department of Material Chemistry, Graduate School of Engineering, Kyoto University, Kyoto-daigaku Katsura, Nishikyo-ku, Kyoto 615-8510, Japan. Fax: +81-75-383-2438; Tel: +81-75-383-2441; E-mail:

40 yori@orgrxn.mbox.media.kyoto-u.ac.jp,

oshima@orgrxn.mbox.media.kyoto-u.ac.jp 